\title{
Ueber die Zusammensetzung des Fibrins, über den Kleber, das Albumin und Casein; von Bouchardat.
}

Fibrin. - Ch e vreul hat gczeigh, dafs das Fibrin inmer Foll enthalte, und man hat allgemein angenommen, dafs dieses, von fetten Materien befreite Produkt, eine reine Verbindung sey. Ich werde zu beweisen suchen, dafs diese Annahme nicht gegründet ish, und dafs der Körper, welchen die Chemiker mit Fibrin bezeichnen, cin complexes, aus drei verschiedenen Stoffen bestehendes Produkt ist.

Zur Vermeidung jedes Doppelsinnes erwähne ich hier, dals es sich hier immer um Blutfibrin handeln wird, sey es nun durch Schlagen dieser Flüssigkeit erhalten oder durch Stehenlassen, was unter gewissen Bedingungen zur Bildung einer den Pathologen unter dem Namen Eıtzündungshäutchen bekannten Pseudomembrane Veranlassung gibt.

Wenn man das Entzündungshäutchen von dem Blute der an acuter Pleuropneumonie oder acutem Cliederrhcumatismus Leidenden abnimmt, es sorgfältig zur Entfernung der Kügelchen wäscht, und wenigstens 24 Stunden lang maceriren läfst unter önerer Emeuerung des Waschwassers, um es ganz weifs und frei von aller löslichen, ciweifsartigen Materie zu erhalten, so hat man alsdann eine undurchsichtige, zähe, ganz weilse Membran.

Man halto dieses Produkt bisher als feuchles, wechselnde Mengen von Felt enthaltendes Fibrin betrachtet, der nachstehende Versuch zeigt aber augenscheinlich seine complexe Zusammensetzung.

Wenn man diese feuchte Pseudomembrane mit dem $3-4$ fachen Gewicht Wasser bis auf die Hälfte einkocht und das kochende Decoct durchseiht, so erhält man bei gehörigem Erkalten enlweder eine dicke Flussigkeit oder sclbst eine ganz consistente 
Gallerte. Nan kann diese Gallerte in gelínder Wärme von Neuem flüssig machen. Versetzt man diese Flüssigkeit vorsichtig mit Salpetersāure, so entsteht kein Niederschlag oder eine kaun merkliche Trübung; wenn man dagegen eine Auflösung von Quecksilberchlorid oder von Gerbstoff hinzufügt, so bildel sich sogleich ein reichlicher, flockiger Niederschlag; leitet man Chlor hinein, so bemerkt man ebenfalls die Bildung reichlicher Flocken.

Diese Versuche zeigen, dals das aus dem Blute dargestellto Fibrin Leim enthalte.

Ich suchte durch zahlreiche Versuche ausfindig zu machen, in wetchen Verhältnissen zu den andern Bestandlheilen der Leim in dem Fibrin vorhanden ist, ohne indessen diese Frage mit Schärfe lösen zu können; dieses Verhältnifs ist in der That ausserordentlich wechseind. Im nornalen Zustand, in dem Fibrin des gesunden Menschen ist es biswcilen schwierig die Giegenwart von Leim deutlich nachzuweisen; bei entzündlichen Affeclionen der serösen Haut oder des Zellgewebes kann es dagegen in nicht unbeträchtlicher Menge zugegen seyn. Es ist leicht begreiflich, dafs die Verhältnisse dieser organischen Bestandlheile in Folge von Nalırungs - oder Krankheitsverhältnissen unausgesetzt wechselı künnen.

Die Gegenwart von Leim, in dem Blut der an acuten, entzündlichen Affectionen der serōsen Häule, oder des Zellgewebes Leidenden ist eine der Aufmerksamkeit der Pathologen würdig७ Thatsache.

Aufser dem Leim enthält das von Felt befreite Fibrin noch zwei andere Substanzen; diese wichlige Thatsache kunn durch die Einwirkung sehr verdünnter Säuren auf das Fibrin nachgewicsen werden.

Bringt man feuchtes Fibrin in Wasser, welches ein halb Tausendtel Salzsăure enthält, (cine Verdünnung, wo die Sảure lkaum durch den Geschmack bemerkbar ist), so scliwillt es sogleich auf und verwandelt sich in eine Anhäufung von gallert- 
artigen, sehr voluminüsen Flocken; bei fortgesetzter Mlaceration zerreissen die strolzenden Blëschen, der gröfsle Theil des Fibrins löst sich auf, es bleibt aber immer eine Quantität eines Produkis zurück, das durch einen Veberschufs des Aunlösungsmittels nicht angegrifen wird und das ausser Fett aus einer Substanz besteht, die mir mit der Maleric identisch zu seyn scheint, welche die Grundlage der Epidermis oder auch der Horngebilde ausnuacht.

Das Verhältnifs dieser ungelösten Substanz, für welche jeh den Namen Epidermose vorschiage, ist zienilich gering; es ist sehwierig genau zu bestimmen, da es von der aufgelösten Substauz nur durch Filtration geschieden werden kann, und diesc Operation bei einer schleimigen, sehr veründerliclien Flüssigkeil kaum eine quantitativo Bestimnung zulärst.

Der Antheil des Fibrins, der durch angesäuertes Wasser so leicht aufgelöst wird, machh, wie später gezeigt werden wird, den wesentlichen Bestundtheil der verbreitetsten stickstomhattigen Materien, des Albumius der Eier, des Blutes, des Caseins und endlich des Hauptbestandtheils des rohen Getreideklebers aus.

Die saure Auflösung des Fibrins rötheł kaum das Lacmuspapier; durch überschüssige Salz - und Salpetersäure etc. wird sie reichlich gefält, ein grofser Veberschufs an Säure lüst den ontstandenen Niederschlag wioder auf. In der Wärme trübt sie sich und setzt leichte Flocken ab, es wird aber nicht alles gefallt, der gröfste Theil bleibt bei vorsichligem Verdampfen der Flüssigkeiten in dünnen, darchsichtigen, biegsamen, schwach gefärbten Hüutchen zurück.

Dic saure Fibrinlösung wird fenner durch Quecksilberchlorid, Blutlaugensalz und Gerbstoff gefällt. In dem Biot'schen Apparate lenkt sie die Strahlen des polarisirten Lichtes links ab; die Rotation ist aber immer nur uubeträchtlich, selbst in einer sehr langen Rðhre, da die Aufösungen nur weniz mit Substanz beloden sind. Der ueben dem Leim in dem Fibrin onthaltene 
Iosliche Bestandtheil ist identisch mit dem Hauptbestandtheil dea Allumins der Eier, wershalb ich ihn Albuminose nenne.

Die saure Aufösumg enthält nicht allein Albuminose, sondern auch Leim, da letzteror, wic folgender Versuch zeigt, in der nümlichen verdünnten Sāure löslich ist.

Legl man trockene Hausenblase in Blättern oder die Membranen, woraus die Schwimmblase des Accipenser Huso besteht, in mit ein balb Tausendtel Salzsäure angesãuertes Wasser, und erwärmt das Ganze auf ungefähr $20^{\circ}$, so schwillt sie auf, zertheilt sich und löst sich zum grörsten Theil. Filtrirt man mach 12stündiger Einwirkung ab, so hat man eine Auflōsung, die beim Erkálten um einige Grade zu einer ganz durchsichtigen, kaum sauer schmeckenden, consistenten Gallerte gesteht.

Dieser Versuch zeigt, dals in dem rohen, in schwach angesảuertem Wasser löslichen Fibrin zwei Materieu, Leim und Albuminose vorhanden sind. Die saurc Auflōsung des Fibrins enthält beide Körper.

Es ist ferner hierdurch die Präexistenz des Leims in den thierischen Geweben nachgewiesen, wenn man sicht annehmen will, dafs das Wasser, dessen Säuregehalt kaum fähig ist Lacmus zo rüthen, bei gewöbnlicher Temperatur diese Umuaodlung bewirken kann.

Eintoirking verschiedenter perdïnnler Säturen auf das Fibrin. - In verdiinnten Anflösungen, dje nur ein halb Tausendiel ron Milchsāure, Essigsãure, Schwefelsämre, Salpetersãure und Phosphorsäure enthalten, schwillt das Fibrin, gerade wie in der Salzsāure auf, und löst sich zum Theil; die Auflösung geht aber schneller und vollkommener mit Salzsäurc, als nit den andern sauren Flüssigkeiten vor sicb. Es isł jedenfalls aher erwiesen, dafs es keine, der verdünnten Salzsäure eigentluünliche Wirkung ist; sie erstreckt sich auch auf andore eben so verdümnte Sänren, selbst auf dia, welche in eiweifshaltigen Flüsigkeiten einen 
124 Bouchardat, über die Zusammonsctaung des Fibrins,

Niederschlag hervorbringen und damit unlöslichc Verbindungen eingehen.

hleber. - Wenn inan Getreideklcher in Wasser bringl, das $1 / 2-2$ Tausendtel Salzsïure enthält, so zcrtheilt er sich, löst sich nach und nach und man erhält beim Fillriren eine klare Flüssigkeit, die sich gerade wie dic saure Aunösung von Albuminose verhält. Sie trübt sich eluenfalls bcim Kochen, wird durch Salz - und Snlpetersäure u. s. w. gefällt, der Niederschlag löst sich in eineın grofsen Ueberschuðs der nàmlichen Säuren wieder auf. Sic wird ferner durch Quecksilberchlorid, durch Blutlaugensalz und durch alle liörper gefalli, die auch das Nbunin uiederschlagen.

Das Rotationsvermögen dieser Substanz ist ganz dassclbe, wie das des Albuminose aus Fibrin, es lenkt die Strahlen in derselben Richtung $a b$, die Intensität der Ablenkung ist viel stärker; die Auflusung bann auch concentrirter seyn, da man in dem rohen Kleber nicht die von mir Epidernsose genannte Substanz findet, dio das Albuminose in den Fibrinhüllen einschliefst und dershalb die leichtere Auflösung verhindert.

Albumin des Blutes and der Eier. - Vertheilt man Blutscrum in $1-2$ Tausendtel Salzsäurehaltigem Wasser, so erhält man eine Auflōsung, Jic ahsolut wie die saurc Lösung des Nlbuminose aus Fibrin sich verlält und auf das polarisirte Licht die nämliche Ablenkung nach links uusübt, wic Biot beobaclitet lat. Eiweifs aus Eiern scheidet, in angesäucrtem Wasser vertheilt, Häule $a b$, die von diesem lösungsmittel nicht melır angegriffen werden; es löst sicb die von mir mit Albuminose bezeichnele Substanz oder die reine Eiweifsmalcrie auf.

Casein. - Von geronuener Milch wurde, nach 48stündiger Auf bewahrung, sorgfältig der Rahım abgenommen; der Käsestoff wurde auf ein Filler geworfen. und mit kallem Wasser vollkommen ausgewaschen; er wurde nun noch feucht in Wasser vertheilt, das ein halb Tansendtel Salzsäure enthielt. Nach 
einigen Stunden war aller Käsestoff anfigelöst, indem nur einige Spuren von felten Malerien zurück blieben, welche die Flüssigkcit Irübten. Durch Filtration wurde eine klare, schwachsaure Flüssigkeit crhalten, welche alle Eigenschanten einer Auflösung von Albuminose hatle.

Die wichtigsten Schlüsse, die sich aus vorstchenden Beobachtungen ergeben, sind folgende:

1. Das von fetten Matcrien befreite Fibrin bestcht aus 3 Stoffen in wcchelnden Verlälınissen: aus einer mit dem reinen, niclit coagulirten Albumin idcntischen Malerie, für welche ich den Nanen Allouminose vorschlage. Dieses flussige Albuminose ist in dem Netz eines Gewebes enthalten, das aus Leim und cinem Stoffe zusammen geselzt ist, der alle Eigenschaften der Epidermisbildung hat und welchen ich aus diesem Grunde Epidermose nenne.

Ich gehe hicr nicht näher auf die Schlüsse ein, die man aus dieser complexen Zusammensetzung des Fibrins ziehen kann, und erwähne nur noch, dafs nun zwci Hauptheslandtheile der thierischen Gewebe, der Lein und das Epidermose in dem Blute nachgewiesen sind, worit ihre Existenz noch nicht dargethan war.

2. Der Hauptbestandtheil des Albumins ans Eiern, aus dem Serum des Bluts, aus dem Kileber der Cerealien und dem Käse der Thiermilch; ist immer identisch; es ist das Albuminose, gemengt oder verbunden mit erdigen Materien, phosphorsaurem Kalk und Bitlererde, so wie mit alkalischen Salzen und fetten Substanzen, welche seine wesentlichen Eigenschanten maskiren. Zersetzt man durch cine wirklich unbestiminbare Menge Säure diese lose Verbindung, so besilzt alsdann die Auflösung des Albuninose ein ganz gleiches chemisches und physikalisches Verhalten.

(Compt. rend. T. XIV. p. 962.) 